\title{
Identifying Homogeneous Patterns of Injury in Paediatric Trauma Patients to Improve Risk-Adjusted Models of Mortality and Functional Outcomes
}

\author{
Joanna F. Dipnall ${ }^{1,2, *(\mathbb{C} \text {, Belinda J. Gabbe }}{ }^{1,3}$, Warwick J. Teague ${ }^{4,5,6}$ and Ben Beck ${ }^{1,7}$ (1) \\ 1 School of Public Health and Preventive Medicine, Monash University, Melbourne, Victoria 3004, Australia; \\ belinda.gabbe@monash.edu (B.J.G.); Ben.Beck@monash.edu (B.B.) \\ 2 School of Medicine, Deakin University, Geelong, Victoria 3220, Australia \\ 3 Health Data Research UK, Swansea University Medical School, Swansea University, Swansea SA2 8PP, UK \\ 4 Trauma Service, The Royal Children's Hospital, Melbourne, Victoria 3052, Australia; \\ w.teague@unimelb.edu.au \\ 5 Department of Paediatrics, University of Melbourne, Melbourne, Victoria 3052, Australia \\ 6 Surgical Research Group, Murdoch Children's Research Institute, Melbourne, Victoria 3052, Australia \\ 7 Faculty of Medicine, Laval University, Quebec City, QC G1V 0A6, Canada \\ * Correspondence: jo.dipnall@monash.edu
}

Received: 17 December 2019; Accepted: 27 January 2020; Published: 31 January 2020

check for updates

\begin{abstract}
Injury is a leading cause of morbidity and mortality in the paediatric population and exhibits complex injury patterns. This study aimed to identify homogeneous groups of paediatric major trauma patients based on their profile of injury for use in mortality and functional outcomes risk-adjusted models. Data were extracted from the population-based Victorian State Trauma Registry for patients aged 0-15 years, injured 2006-2016. Four Latent Class Analysis (LCA) models with/without covariates of age/sex tested up to six possible latent classes. Five risk-adjusted models of in-hospital mortality and 6-month functional outcomes incorporated a combination of Injury Severity Score (ISS), New ISS (NISS), and LCA classes. LCA models replicated the best log-likelihood and entropy $>0.8$ for all models $(\mathrm{N}=1281)$. Four latent injury classes were identified: isolated head; isolated abdominal organ; multi-trauma injuries, and other injuries. The best models, in terms of goodness of fit statistics and model diagnostics, included the LCA classes and NISS. The identification of isolated head, isolated abdominal, multi-trauma and other injuries as key latent paediatric injury classes highlights areas for emphasis in planning prevention initiatives and paediatric trauma system development. Future risk-adjusted paediatric injury models that include these injury classes with the NISS when evaluating mortality and functional outcomes is recommended.
\end{abstract}

Keywords: latent class analysis; risk adjustment; paediatric; trauma; injury; mortality, $\mathrm{KOSCHI}$, classes

\section{Introduction}

Injuries in children make a considerable contribution to disease burden globally, being a leading cause of mortality for children over one year of age and causing varying levels of disability affecting their development into adulthood [1]. a 10-year review of the injury outcomes of children in Australia found that injury was the leading cause of death in children aged 1 to 16 years [2]. The effects of rising globalisation, urbanisation, motorisation and environmental changes all impact on the risks and nature of childhood injuries around the world [3]. However, regardless of age or country, traumatic injuries can be debilitating, affect a variety of regions of the body, cause future physical and/or mental impairment, and can be fatal. 
A single injury event in a child can result in highly variable patterns of injury and severity across age groups [2]. Furthermore, typical types of traumatic injuries are not static through childhood and adolescence, with the cause, pattern and severity of injury varying with age. For example, falls and burns are common in children aged 1 to 5 years as they explore their environment in the context of rapid growth and development [4], whereas the advent of risk-taking behaviour in the ascendency to adolescence introduces mechanisms of injury related to activities such as the use of bicycles $[5,6]$ and off-road vehicles [7,8].

Many studies globally have focused on specific injury subsets (e.g., brain injury [9,10], spinal injuries [11], skeletal fractures [12], thoracic trauma [13]) or used single summary scores of severity such as the Injury Severity Score (ISS) [14] or New ISS (NISS) [15]. These approaches eliminate the ability to characterise patterns of injuries. Gaining a better understanding of the types and patterns of injuries sustained and how multiple injuries cluster together may allow for the improved modelling of injury mortality and functional outcomes.

Latent Class Analysis (LCA) measures one or more unobserved or latent classes inferred from a set of observed categorical variables [16]. This technique has been found to be superior to traditional cluster analysis, as LCA is a model-based approach where the selection of the number of classes is based on a set of statistical indices [17]. This approach has been widely used to create homogenous groups of individuals based on typologies in psychology, educational research and the social sciences [18].

Current risk-adjusted mortality models for paediatric trauma have predominantly used the ISS or NISS to control for the severity of the injury rather than pattern of injury. There is a need to focus on the individual paediatric trauma patient [19] and incorporate homogenous injury patient-centric groupings from LCA in these models. This would enable patterns of injuries to be taken into consideration. Therefore, this study aimed to identify homogeneous groups of paediatric major trauma patients for use in risk-adjusted models of mortality and functional outcome.

\section{Materials and Methods}

\subsection{Sample}

This study used data from the Victorian State Trauma Registry (VSTR) [20]. The VSTR is a population-based registry containing pre-hospital, acute care and long-term outcomes data for all major trauma patients in Victoria, Australia. The Victorian State Trauma System defines 'paediatric' as aged 0 to 15 years, triaging the majority of paediatric major trauma patients to a single, designated paediatric Major Trauma Service (MTS) for definitive care [21]. Patients aged 0 to 15 years at the time of injury, injured between 2006 and 2016 (inclusive), with an ISS greater than 12 [22] were included in this study. The ISS ranges from 1 (least severe) to 75 (most severe) and an ISS $>12$ has been adopted to identify major trauma patients [22]. The VSTR has Human Research Ethics Committee approval from the Department of Health and Human Services (DHHS) for all 138 trauma-receiving hospitals in Victoria, and the Monash University Human Research Ethics Committee (MUHREC) (CF13/3040-2001000165).

\subsection{Measures}

Year of injury, demographics, injury event details, injury diagnoses, injury severity, and other relevant factors were extracted from the VSTR. Demographic data included sex (male, female) and age in years at the time of injury, categorised into four groups [23]: $<1$ year, 1-5 years, 6-10 years, and 11-15 years. The Australia Bureau of Statistics (ABS) Socio-Economic Indexes for Areas (SEIFA) were accessed, with the Accessibility/Remoteness Index of Australia (ARIA) $(0=$ regional, $1=$ major city) and the quintiles for the Index of Relative Socioeconomic Advantage and Disadvantage (IRSAD) (low score $=$ greater disadvantage, high score $=$ greater advantage) were included as indicative measures of socioeconomic status and geographic remoteness. a binary variable was created to indicate if the patient was definitively managed at an MTS $(0=$ No, $1=$ Yes $)$. 
Injury diagnosis codes were assigned by trained coders using the Abbreviated Injury Scale (AIS) (2005 version; 2008 update) [24]. The AIS is an internationally recognised tool for ranking injury severity, and classifies individual injury severity on a six-point scale $(1=$ minor injury to $6=$ maximal (currently untreatable) injury). Sixteen dichotomous injury groups were identified $(0=$ no injury present; $1=1$ or more injuries within group) based on the AIS body region and severity (Appendix A). The Injury Severity Score (ISS), New Injury Severity Score (NISS) and number of injuries per patient (i.e., across the sixteen injury groups) were calculated. The ISS is calculated as the sum of squares of the highest AIS code in each of six body regions (head/neck, face, chest, abdominal/pelvic contents, extremities/pelvic girdle, external). If an injury is assigned an AIS of currently untreatable injury, the ISS score is automatically assigned the highest ISS score of 75. The NISS is calculated from the sum of squares of the three highest AIS scores, irrespective of the body region affected.

Mechanism of injury was collapsed into 13 groups: motor vehicle occupant, motorcycle, cyclist, pedestrian, horse-related, low fall from a standing height or $<1 \mathrm{~m}$, high fall from $\geq 1 \mathrm{~m}$, submersion/drowning, other threat to breathing, fire/scalds/contact burn, cutting, piercing object, struck by or collision with person/object, and "other" cause.

Binary measures of in-hospital mortality $(1=$ died, $0=$ alive $)$ and the Kings Outcome Score for Closed Head Injury (KOSCHI) scale [25] ( $1=$ died in hospital/disability, $0=$ good/intact recovery), administered at 6 months by telephone, were used for the final regression models.

\subsection{Analyses}

Patients were clustered by hospital to ensure standard errors allowed for intragroup correlation [26]. Individual hospital clusters of $\geq 10$ patients were retained, with four clusters ranging in size from 17 to 1199 patients. Low volume hospitals (i.e., $<10$ patients) were classified into two clusters: metropolitan $(\mathrm{n}=22)$ and regional $(\mathrm{n}=29)$.

The main analyses consisted of six key steps, with steps 1 to 4 related to LCA and steps 5 to 6 related to the final regression models (Figure 1).

Four exploratory LCA Models were generated (M1, M2, M3, M4). To review the sensitivity of the final selection of the latent injury classes, two models excluded patients who sustained asphyxia or burn injuries (Ml and M3), and two models included patients with any asphyxia or burn injuries (M2 and M4). LCA M1 and M2 were initially analysed to establish the classes, then expanded to run the M3 and M4 multinomial logistic regression of the categorical latent variables on the covariates of age group and sex. Probabilities across models were compared to establish if these demographics influenced the latent injury class probabilities and latent classes (i.e., measurement known invariance explaining differences in class probabilities), or improved estimation [27]. Consultation with a paediatric trauma surgeon supported the final latent classes chosen.

The LCA took account of hospital clustering [28] and latent classes one to six were tested for each model to ensure an adequate number of classes were evaluated. Complex mixture modelling used maximum likelihood estimation with robust standard errors. Initial stage optimisations were set, and number of random sets of starting values for the final stage optimisation was set to one quarter of the initial starting values to ensure model estimation converged on the global maximum likelihood [29]. The maximum number of iterations in optimization was set to 20 . 

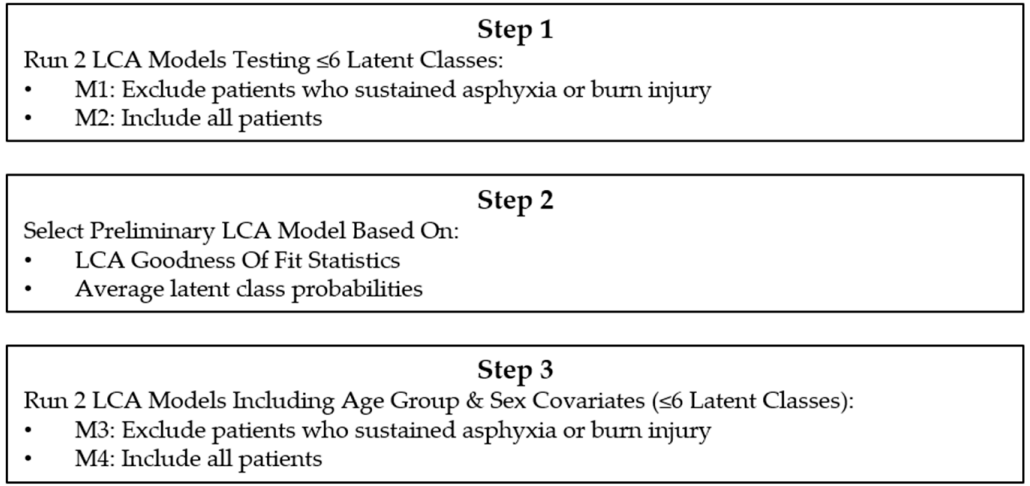

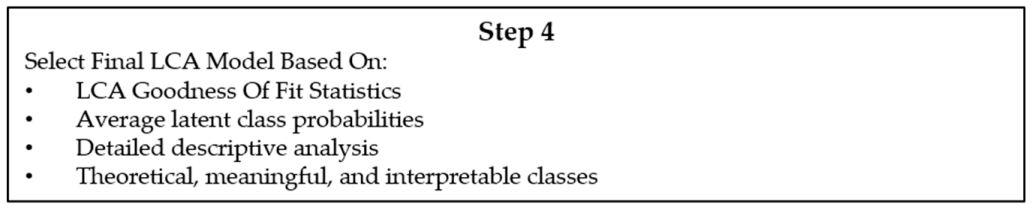

\begin{tabular}{|ll|}
\hline \multicolumn{2}{|c|}{ Step 5 } \\
Run 5 Multivariable Binary Logistic Regression Models For Mortality \& Functional \\
Outcomes: & Inclusion of ISS only (ISS) \\
1. & Inclusion of NISS only (NISS) \\
2. & Inclusion of final latent classes chosen only (LCA) \\
3. & Inclusion of ISS final latent classes chosen (ISS \& LCA) \\
4. & Inclusion of NISS and final latent classes chosen (NISS \& LCA) \\
5. & $\quad$ Step 6 \\
\hline \multicolumn{2}{|c|}{ Evaluate Models Based On Post Estimation Goodness Of Fit Statistics } \\
\hline
\end{tabular}

Figure 1. Flowchart of main analyses.

Goodness of fit statistics were compared to establish the optimal number of classes: Akaike Information Criterion (AIC) [30], Bayesian Information Criterion (BIC) [31], Vuong-Lo-Mendell-Rubin Likelihood Ratio Test (LMR-LR) and adjusted LMR LR (ALMR-LR) test [32], and Entropy [33]. Smaller values of AIC/BIC and higher values for entropy indicated better model fit. The LMR-LR and ALMR-LR compared model fit improvement between models with $\mathrm{k}$ classes and $(\mathrm{k}$ $-1)$ classes. a $p$-value $<0.05$ indicated rejecting the $(k-1)$ class model in favour of at least the current $\mathrm{k}$ class model. The LMR-LR and AMR-LR was applied to further classes to ensure a significant result for $\mathrm{k}+1$ classes ( $p$-value $>0.05$ ). The relative entropy criterion from MPlus was used for assessing the quality of class membership classification: 0.80 was considered high, 0.60 medium and 0.4 as low entropy [34].

Average latent class probabilities represented the proportion of the population expected to belong to a latent class. Estimated posterior probabilities ranged from 0 to 1, where higher posterior probabilities for injuries may indicate the label for that latent class.

Patients were classified into distinctive homogeneous groups, or latent classes, based on their posterior membership probabilities, given the model and the patient's data. Relative proportions of latent classes established adequate proportions per class. Detailed descriptive analysis ensured each latent class was distinctly different, theoretically and substantively meaningful, and interpretable. Differences between the latent classes were explored using chi-square tests with Pearson adjusted residuals (AR) $>|2|$ considered significant [35], and Kruskal-Wallis equality-of-populations rank tests with Dunn's test [36] where appropriate.

Five multivariable logistic regression models were run to investigate the impact of the inclusion of the final latent injury classes on the risk-adjusted models for in-hospital mortality and 6-month functional outcome (KOSCHI) [37], controlling for potential demographic and injury confounders. 
The difference between the five models were inclusion of potential demographic and injury confounders and:

1. Inclusion of ISS only (ISS)

2. Inclusion of NISS only (NISS)

3. Inclusion of final latent classes chosen only (LCA)

4. Inclusion of ISS final latent classes chosen (ISS and LCA)

5. Inclusion of NISS and final latent classes chosen (NISS and LCA)

The following post estimation goodness of fit statistics were used to evaluate each of the models:

1. a BIC where the smaller the better model.

2. a Hosmer-Lemeshow goodness-of-fit test using 10 quantiles where a $p$-value $>0.05$ indicates a good model fit.

3. Percentage sensitivity, specificity and overall percentage correctly classified where the higher the better.

4. McFadden, Adjusted McFadden, McKelvey and Zavoina, Cox Snell, Nagelkerke R-square values where the higher the better.

5. Receiver Operator Curve area (AUC) where the closer to 1 the better.

6. Specification link test for single-equation models where a $p$-value $>0.05$ indicates model correctly specified.

Mplus (Version 8.1) and R (Version 3.5.1) and associated packages [38,39], as well as Stata Version 15.1, were used for this research.

\section{Results}

\subsection{Sample Characteristics}

Of the 1285 patients meeting the inclusion criteria, four were excluded due to no injury profile classified from the AIS.

Males were predominant (66.5\%), and the average age was 8 years (Table 1). Head injuries were the most common (brain injury and/or skull fracture 58.3\%); $22.3 \%$ had sustained an isolated head injury. Falls, either low or high, were the most common injury mechanism $(24.0 \%)$, followed by motor vehicle occupant $(16.2 \%)$, then being struck by or colliding with a person or object (12.4\%) (Table 2). 
Table 1. Patient demographic characteristics.

\begin{tabular}{|c|c|c|}
\hline Characteristic & Models 1 and 2 & Models 3 and 4 \\
\hline Base & 1178 & 1281 \\
\hline \multicolumn{3}{|l|}{$\operatorname{Sex}(n, \%)$} \\
\hline Male & $790(67.1 \%)$ & $852(66.5 \%)$ \\
\hline Female & $388(32.9 \%)$ & $429(33.5 \%)$ \\
\hline \multicolumn{3}{|l|}{ Age Group (n, \%) } \\
\hline$<1$ year & $116(9.8 \%)$ & $122(9.5 \%)$ \\
\hline $1-5$ years & $263(22.3 \%)$ & $326(25.4 \%)$ \\
\hline $6-10$ years & $267(22.7 \%)$ & $278(21.7 \%)$ \\
\hline $11-15$ years & $532(45.2 \%)$ & $555(43.3 \%)$ \\
\hline Age in Years (Mean, SD) & $8.6(5.2)$ & $8.3(5.2)$ \\
\hline \multicolumn{3}{|l|}{ IRSAD Quintile (n, \%) } \\
\hline 1 & $206(17.7 \%)$ & $230(18.2 \%)$ \\
\hline 2 & $210(18.0 \%)$ & $227(17.9 \%)$ \\
\hline 3 & $260(22.3 \%)$ & $281(22.2 \%)$ \\
\hline 4 & $263(22.6 \%)$ & $291(23.0 \%)$ \\
\hline 5 & $225(19.3 \%)$ & $236(18.7 \%)$ \\
\hline \multicolumn{3}{|l|}{ ARIA (n, \%) } \\
\hline Inner regional/outer regional/remote & $394(34.0 \%)$ & $425(33.8 \%)$ \\
\hline Major city & $764(66.0 \%)$ & $834(66.2 \%)$ \\
\hline \multicolumn{3}{|l|}{ Fund (n, \%) } \\
\hline Compensable & $405(34.7 \%)$ & $410(32.3 \%)$ \\
\hline Non-compensable & $762(65.3 \%)$ & $858(67.7 \%)$ \\
\hline \multicolumn{3}{|l|}{ Major Trauma Service (n, \%) } \\
\hline Yes & $1028(87.3 \%)$ & $1112(86.8 \%)$ \\
\hline \multicolumn{3}{|l|}{ Discharge Type (n, \%) } \\
\hline Home & $888(75.4 \%)$ & $940(73.4 \%)$ \\
\hline Rehabilitation & $196(16.6 \%)$ & $202(15.8 \%)$ \\
\hline Hospital for Convalescence & $18(1.5 \%)$ & $18(1.4 \%)$ \\
\hline Other & $16(1.4 \%)$ & $20(1.6 \%)$ \\
\hline In-hospital death & $60(5.1 \%)$ & $101(7.9 \%)$ \\
\hline
\end{tabular}

Table 2. Patient injury characteristics.

\begin{tabular}{lcc}
\hline Characteristic & Models 1 and 2 & Models 3 and 4 \\
\hline Base & 1178 & 1281 \\
Injury Type (n, \%) & & \\
Head-brain injury & $503(57.3 \%)$ & $605(52.8 \%)$ \\
Head-skull fracture & $381(32.3 \%)$ & $381(29.7 \%)$ \\
Neck injuries & $9(0.8 \%)$ & $10(0.8 \%)$ \\
Cervical spine-spinal cord injury (SCI) & $39(3.3 \%)$ & $39(3.0 \%)$ \\
Cervical spine-non-SCI & $18(1.5 \%)$ & $18(1.4 \%)$ \\
Thoracolumbar spine-SCI & $20(1.7 \%)$ & $20(1.6 \%)$ \\
Thoracolumbar spine-non-SCI & $19(1.6 \%)$ & $19(1.5 \%)$ \\
Thoracic organ injuries & $152(12.9 \%)$ & $153(11.9 \%)$ \\
Skeletal chest injuries & $55(4.7 \%)$ & $55(4.3 \%)$ \\
Abdominal organ injuries & $246(20.9 \%)$ & $246(19.2 \%)$ \\
Upper limb injuries & $193(16.4 \%)$ & $193(15.1 \%)$ \\
Lower limb injuries & $169(14.3 \%)$ & $170(13.3 \%)$ \\
Pelvis injuries & $73(6.2 \%)$ & $74(5.8 \%)$ \\
Vascular injuries & $20(1.7 \%)$ & $20(1.6 \%)$ \\
Asphyxial injury & Excluded & $65(5.1 \%)$ \\
Burn injury & Excluded & $38(3.0 \%)$ \\
\hline
\end{tabular}


Table 2. Cont.

\begin{tabular}{lcc}
\hline Characteristic & Models 1 and 2 & Models 3 and 4 \\
\hline ISS (Median, IQR) & $17.0(16.0,26.0)$ & $17.0(16.0,26.0)$ \\
NISS (Median, IQR) & $25.0(17.0,34.0)$ & $25.0(17.0,34.0)$ \\
Six-Month KOSCHI & & \\
Death in hospital/disability & $401(57.4 \%)$ & $463(60.4 \%)$ \\
Good/intact recovery & $298(42.6 \%)$ & $304(39.6 \%)$ \\
Total Injuries (Median, IQR) & $2.0(1.0,2.0)$ & $1.0(1.0,2.0)$ \\
Mechanism of Injury (n, \%) & & \\
Motor vehicle occupant & $207(17.6 \%)$ & $208(16.2 \%)$ \\
Motorcycle & $123(10.4 \%)$ & $124(9.7 \%)$ \\
Cyclist & $118(10.0 \%)$ & $118(9.2 \%)$ \\
Pedestrian & $143(12.1 \%)$ & $143(11.2 \%)$ \\
Horse-related & $40(3.4 \%)$ & $40(3.1 \%)$ \\
Low fall & $168(14.3 \%)$ & $168(13.1 \%)$ \\
High fall & $139(11.8 \%)$ & $139(10.9 \%)$ \\
Submersion/drowning & Excluded & $52(4.1 \%)$ \\
Other threat to breathing & Excluded & $12(0.9 \%)$ \\
Fire/scalds/contact burn & Excluded & $36(2.8 \%)$ \\
Cutting, piercing object & $13(1.1 \%)$ & $13(1.0 \%)$ \\
Struck by or collision with person/object & $159(13.5 \%)$ & $159(12.4 \%)$ \\
Other & $68(5.8 \%)$ & $69(5.4 \%)$ \\
\hline
\end{tabular}

\subsection{Latent Class Analysis}

Fit information from the LCA were generally consistent across models. All models replicated the best log-likelihood. Based on a combination of the fit criterion and evaluation of the posterior probabilities, three latent classes were selected from M1 and M3; four latent classes were selected from M2 and M4. The largest decline in both AIC and BIC was between latent classes one to three for M1 and M3, and one to four for M2 and M4 (Figure 2). The BIC was lowest at latent classes three for all models; however, the four latent injury class models were selected for M2 and M4 as the BIC was virtually the same (i.e., $<0.01 \%$ difference) but the entropy was higher and the classes made theoretical sense. The LMR-LR and ALMR-LR did not reach a significant result for the models, but the entropy values for all Models were above 0.8 .

Figure 3 presents the prevalence of each latent injury class and the predicted probability that patients assigned to an injury class would have certain injuries for each model. Models 1 and 3 represented three latent classes: one was dominated by isolated head injuries (M1: 48.6\%; M3: 49.4\%); one represented multiple injuries (multi-trauma) (M1: 35.2\%; M3: 34.4\%); and one was dominated by isolated abdominal organ injuries (M1: 16.3\%; M3: 16.2\%). Three of the four latent injury classes for M2 and M4 were consistent with M1 and M3: isolated head injuries (M2: 45.3\%; M4: 45.6\%); multi-trauma injuries (M2: 29.0\%; M4: 31.1\%); and isolated abdominal organ injuries (M2: 15.2\%; M4: 15.0\%). Final latent injury classes consisted of the neck injuries, spinal injuries, vascular injuries, asphyxia and burns (M2: 10.4\%; M4: 8.3\%). For convenience, this class was labelled as 'other' as it reflected the low numbers of paediatric major trauma patients with neck, spinal, vascular, and was dominated by asphyxia and burn injuries. 


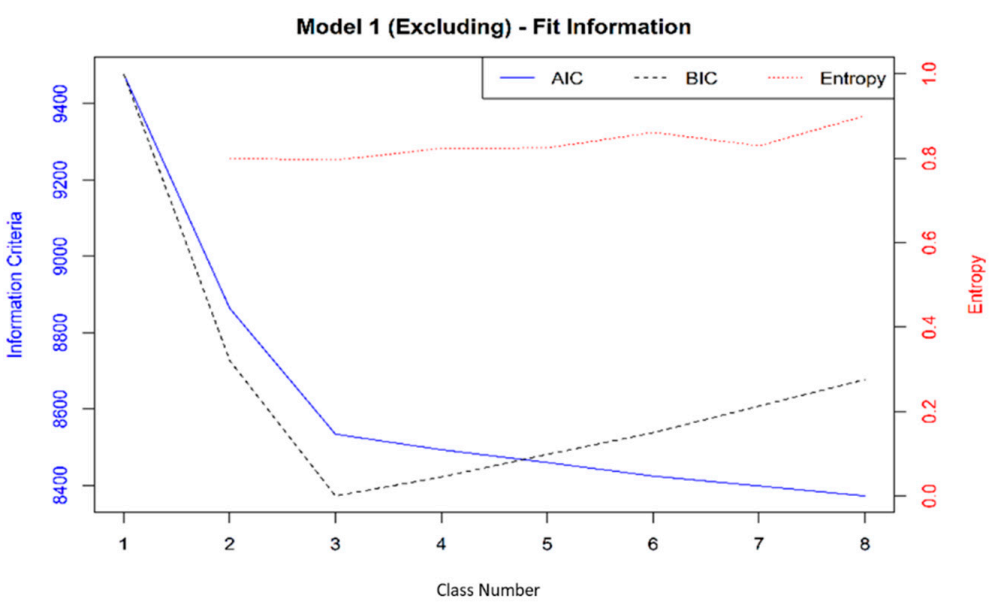

(a)

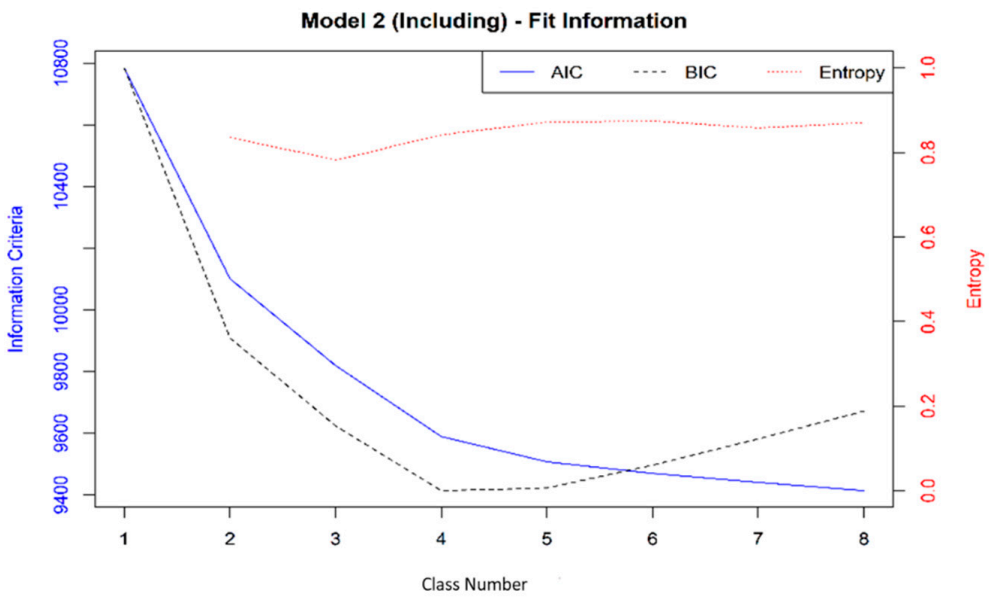

(b)

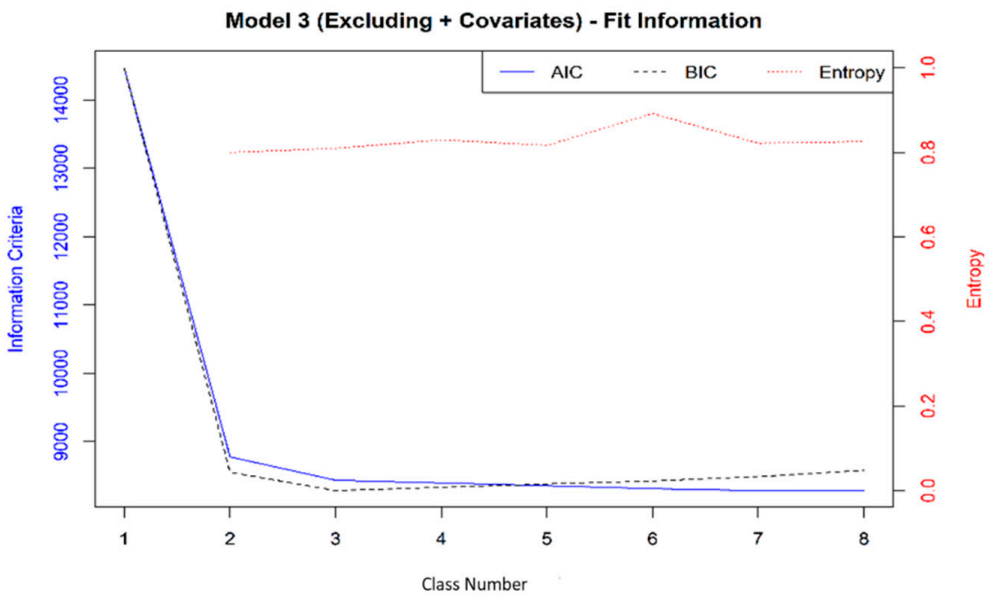

(c)

Figure 2. Cont. 


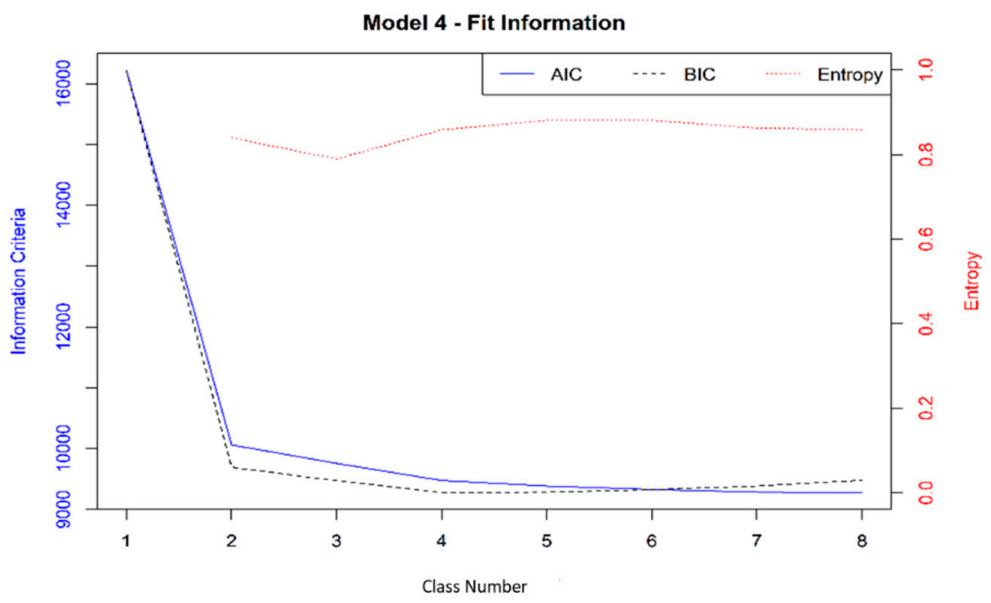

(d)

Figure 2. LCA Model's AIC, BIC and Entropy. (a) Model 1, (b) Model 2, (c) Model 3, (d) Model 4.

Model 1

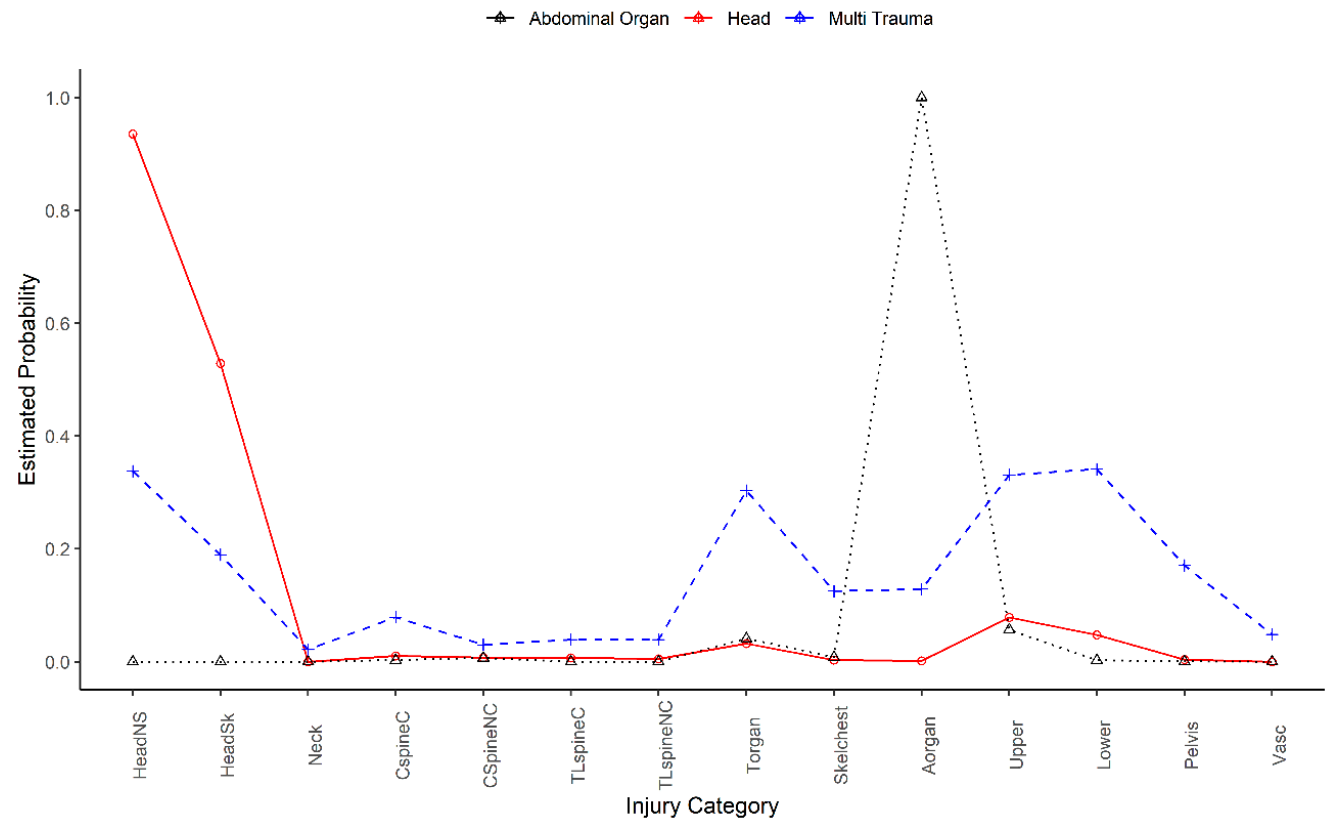

(a)

Figure 3. Cont. 
Model 2

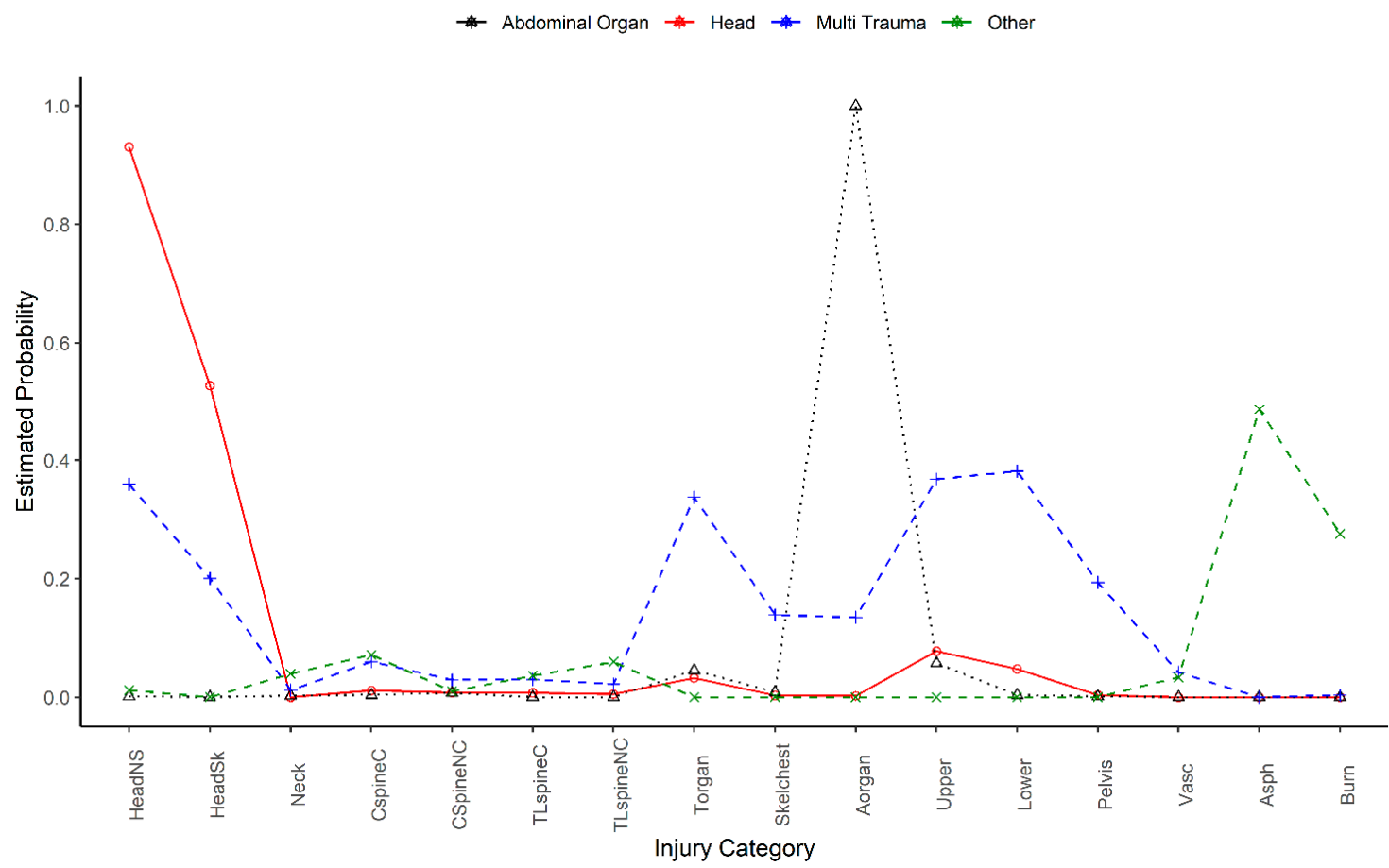

(b)

Model 3

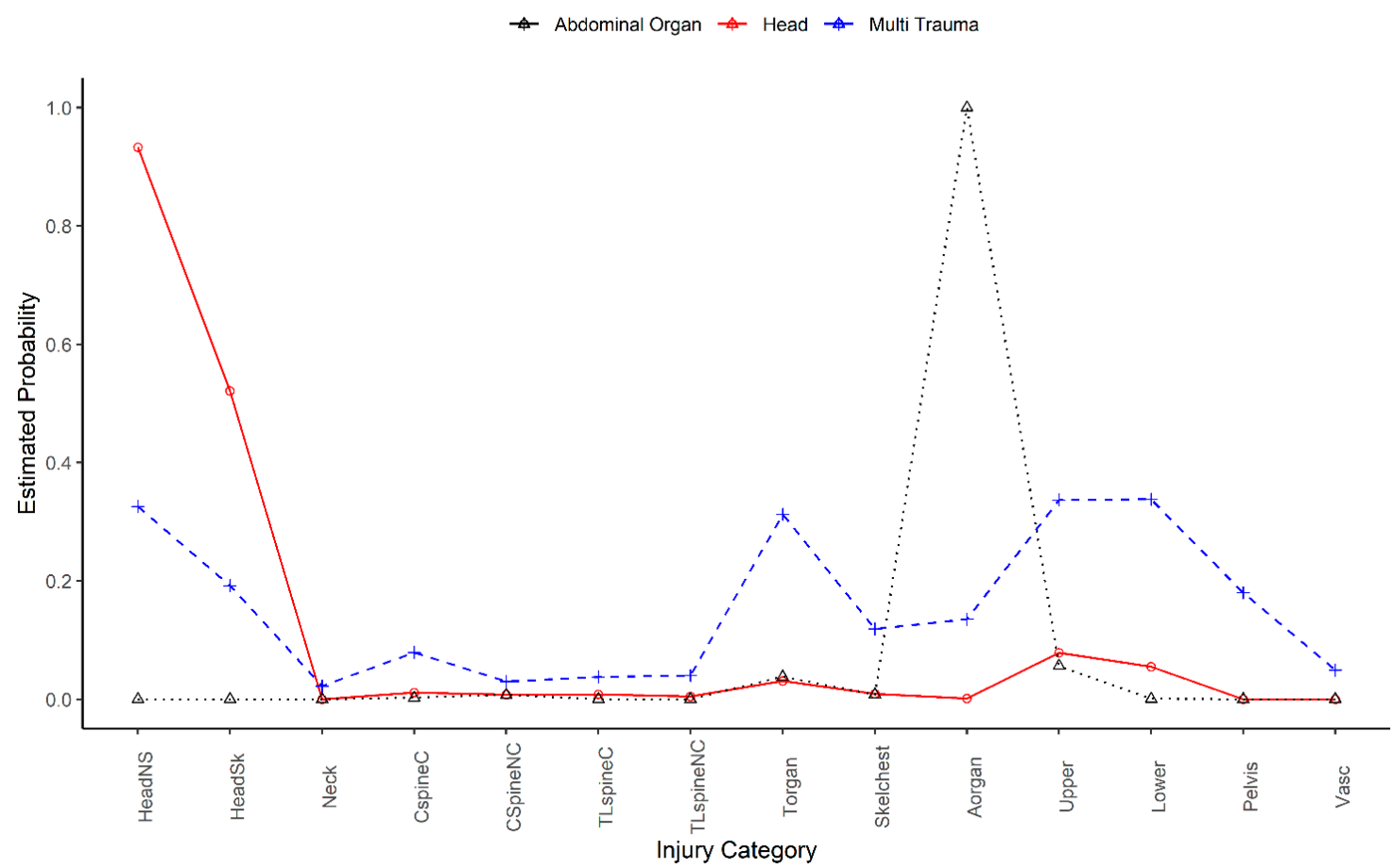

(c)

Figure 3. Cont. 
Model 4

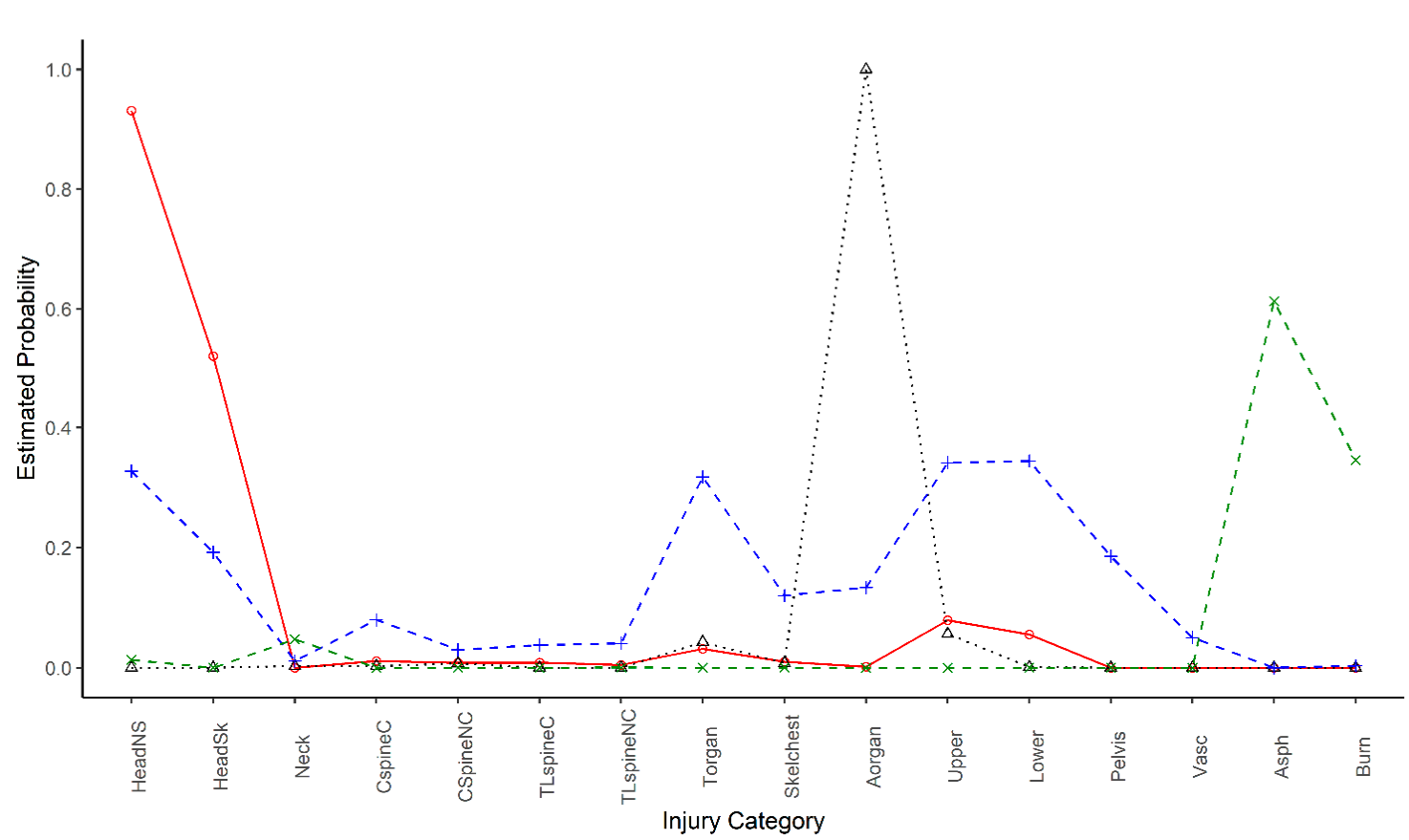

(d)

Figure 3. Estimated probabilities of Latent Classes (a) Model 1 (M1); (b) Model 2 (M2); (c) Model 3 (M3); (d) Model 4 (M4). Note: HeadNS = Head-brain injury, HeadSK = Head-skull fracture, Neck $=$ Neck injuries, CspineC $=$ Cervical spine-spinal cord injury (SCI), CSpineNC $=$ Cervical spine-non-SCI, TLspineC = Thoracolumbar spine-SCI, TLspineNC = Thoracolumbar spine - non-SCI, Torgan $=$ Thoracic organ injuries, Skelchest $=$ Skeletal chest injuries, Aorgan $=$ Abdominal organ injuries, Upper $=$ Upper limb injuries, Lower $=$ Lower limb injuries, Pelvis $=$ Pelvis injuries, Vasc $=$ Vascular injuries, Asph = Asphyxial injury, Burn = Burn injury.

Exploratory analysis of the ARs for key characteristics across the final latent classes chosen found a number of consistent differences across the latent classes for the four models (Table 3). Patients associated with the isolated head injury latent class were more likely to be in the $0-5$ years age group, discharged for rehabilitation, and had falls (low/high) or were struck by or collided with a person/object as their mechanism for injury. Patients associated with the multi-trauma latent class were more likely to be in the 11-15 years age group, discharged to rehabilitation and had been a motor vehicle occupant or pedestrian or riding a motorcycle as their mechanism for injury. Those associated with the isolated abdominal latent class were more likely to be male, in the 6-15 years age group, discharged directly to home and been a motorcyclist, cyclist or struck by or collision with person/object as their mechanism for injury. 
Table 3. Significant Adjusted Residuals (AR) for key characteristics across final latent classes.

\begin{tabular}{|c|c|c|c|c|}
\hline Head Injuries & Model 1 & Model 2 & Model 3 & Model 4 \\
\hline Less than 1 year of age & 6.58 & 6.66 & 7.68 & 8.20 \\
\hline $1-5$ years of age & 4.92 & 2.08 & 5.36 & 2.37 \\
\hline Discharged for rehabilitation & 2.19 & 3.26 & - & 2.51 \\
\hline Mechanism-low falls & 8.27 & 9.22 & 8.18 & 9.25 \\
\hline Mechanism—high falls & 4.28 & 5.34 & 4.37 & 5.36 \\
\hline $\begin{array}{l}\text { Mechanism-struck by or } \\
\text { collision with person/object }\end{array}$ & 2.09 & 3.06 & 2.34 & 3.59 \\
\hline \multicolumn{5}{|l|}{ Multi-Trauma } \\
\hline $11-15$ years of age & 4.26 & 4.51 & 5.58 & 6.70 \\
\hline Discharged to rehabilitation & 3.29 & 2.61 & 3.72 & 4.52 \\
\hline $\begin{array}{l}\text { Mechanism-motor vehicle } \\
\text { occupant }\end{array}$ & 6.63 & 7.44 & 6.58 & 7.41 \\
\hline Mechanism-motorcycle & 3.09 & 4.33 & 3.37 & 4.19 \\
\hline Mechanism-pedestrian & 5.76 & 7.65 & 6.03 & 7.07 \\
\hline \multicolumn{5}{|l|}{ Isolated abdominal } \\
\hline Male & 2.84 & 3.03 & 2.79 & 3.03 \\
\hline $6-10$ years of age & 2.67 & 3.19 & 2.72 & 3.00 \\
\hline $11-15$ years of age & 3.93 & 4.41 & 4.00 & 4.56 \\
\hline Discharged directly home & 7.23 & 7.77 & 7.43 & 7.77 \\
\hline Mechanism-motorcycle & 4.31 & 4.78 & 4.34 & 4.78 \\
\hline Mechanism-cyclist & 5.64 & 6.20 & 5.68 & 6.20 \\
\hline $\begin{array}{l}\text { Mechanism-struck by or } \\
\text { collision with person/object }\end{array}$ & 2.01 & 2.54 & 2.04 & 2.54 \\
\hline
\end{tabular}

Note: - denotes standardized AR $<|2|$.

\subsection{Logistic Regression}

\subsubsection{Mortality Models}

The four latent injury classes from M4 were used for the mortality regression models. Patients with asphyxia injuries were separated out from the other latent class due to their threat to life differing from those patients with burns and the other injuries in this latent class. The results from the five logistic regression models for mortality indicated the best performing mortality model contained both the NISS and the modified latent classes, yielding the lowest BIC, a high sensitivity, specificity, overall correctly classified percentage and highest R-squared values and AUC (Table 4, Appendix B). In addition, the Hosmer-Lemeshow statistic indicated the model was a good fit, without specification error issues. 
Table 4. Mortality logistic regression models.

\begin{tabular}{|c|c|c|c|c|c|}
\hline Model & $\begin{array}{c}\text { (1) } \\
\text { ISS } \\
\text { OR (s.e.) }\end{array}$ & $\begin{array}{c}(2) \\
\text { NISS } \\
\text { OR (s.e.) }\end{array}$ & $\begin{array}{c}\text { (3) } \\
\text { LCA }^{\wedge} \\
\text { OR (s.e.) }\end{array}$ & $\begin{array}{c}\text { (4) } \\
\text { ISS and LCA } \\
\text { OR (s.e.) }\end{array}$ & $\begin{array}{c}(5) \\
\text { NISS and LCA } \\
\text { OR (s.e.) }\end{array}$ \\
\hline Base & 1259 & 1259 & 1259 & 1259 & 1259 \\
\hline ISS & $\begin{array}{l}1.149^{* * *} \\
(0.007)\end{array}$ & & & $\begin{array}{l}1.161^{* * *} \\
(0.008)\end{array}$ & \\
\hline NISS & & $\begin{array}{l}1.111^{* * *} \\
(0.005)\end{array}$ & & & $\begin{array}{l}1.13^{* * *} \\
(0.009)\end{array}$ \\
\hline \multicolumn{6}{|l|}{ LCA Class } \\
\hline Head & & & Reference & Reference & Reference \\
\hline Multi-trauma & & & $\begin{array}{l}1.295^{* *} \\
(0.107)\end{array}$ & $\begin{array}{l}0.705^{* * *} \\
(0.059)\end{array}$ & $\begin{array}{c}2.474^{* * *} \\
(0.169)\end{array}$ \\
\hline Abdominal Organ & & & $\begin{array}{c}0.190^{* *} \\
(0.099)\end{array}$ & $\begin{array}{c}0.221 \\
(0.253)\end{array}$ & $\begin{array}{c}0.988 \\
(1.051)\end{array}$ \\
\hline Asphyxia & & & $\begin{array}{l}21.130 * * * \\
(4.921)\end{array}$ & $\begin{array}{l}29.957^{* * *} \\
(5.895)\end{array}$ & $\begin{array}{c}135.185^{* * *} \\
(30.330)\end{array}$ \\
\hline Burns and other & & & $\begin{array}{c}0.843 \\
(0.149)\end{array}$ & $\begin{array}{c}0.681 \\
(0.328)\end{array}$ & $\begin{array}{c}4.155^{* * *} \\
(1.678)\end{array}$ \\
\hline \multicolumn{6}{|l|}{ Fit Statistics } \\
\hline BIC & 481.93 & 471.55 & 546.90 & 411.30 & 373.68 \\
\hline Sensitivity \% & 85.86 & 88.89 & 76.77 & 83.84 & 88.89 \\
\hline Specificity $\%$ & 82.07 & 82.41 & 78.45 & 87.59 & 90.09 \\
\hline Overall $\%$ correctly classified & 82.37 & 82.92 & 78.32 & 87.29 & 89.99 \\
\hline $\begin{array}{c}\text { Hosmer-Lemeshow } \\
\text { goodness-of-fit test ( } p \text {-value) }\end{array}$ & 0.430 & 0.246 & 0.850 & 0.479 & 0.743 \\
\hline McFadden $\mathrm{R}^{2}$ & 0.357 & 0.372 & 0.263 & 0.458 & 0.513 \\
\hline Adjusted McFadden $\mathrm{R}^{2}$ & 0.342 & 0.357 & 0.248 & 0.444 & 0.498 \\
\hline McKelvey and Zavoina $\mathrm{R}^{2}$ & 0.507 & 0.529 & 0.398 & 0.558 & 0.587 \\
\hline Cox Snell $\mathrm{R}^{2}$ & 0.178 & 0.185 & 0.135 & 0.223 & 0.246 \\
\hline Nagelkerke $\mathrm{R}^{2}$ & 0.421 & 0.437 & 0.318 & 0.527 & 0.581 \\
\hline AUC & 0.916 & 0.917 & 0.853 & 0.940 & 0.951 \\
\hline Specification link test ( $p$-value) & $<0.001^{* * *}$ & $0.029 * *$ & 0.139 & $0.077^{*}$ & 0.587 \\
\hline
\end{tabular}

OR = Odds Ratios, s.e. $=$ Standard errors. ${ }^{* * *} p<0.001,{ }^{* *} p<0.05$. ${ }^{\wedge}$ LCA modified to contain a separate group for Asphyxia injuries. Cut point for sensitivity $\%$, specificity $\%$ and overall $\%$ correctly classified set to proportion died $=0.08$.

\subsubsection{Functional Outcome Models}

As with the mortality modelling, the results from the five logistic regression models for the functional outcome models indicated the best performing functional outcomes model contained both the NISS and modified latent classes, yielding the lowest BIC, a high sensitivity, specificity, overall correctly classified percentage and the highest R-squared values for three of the four measures (Table 5, Appendix B). There was only a marginal difference in the AUC between models (4) and (5), but the Hosmer-Lemeshow statistic indicated model (5) was superior, without specification error issues. 
Table 5. Functional outcome logistic regression models

\begin{tabular}{|c|c|c|c|c|c|}
\hline Model & $\begin{array}{c}\text { (1) } \\
\text { ISS } \\
\text { OR (s.e.) }\end{array}$ & $\begin{array}{c}\text { (2) } \\
\text { NISS } \\
\text { OR (s.e.) }\end{array}$ & $\begin{array}{c}\text { (3) } \\
\text { LCA^ } \\
\text { OR (s.e.) }\end{array}$ & $\begin{array}{c}(4) \\
\text { ISS and LCA } \\
\text { OR (s.e.) }\end{array}$ & $\begin{array}{c}(5) \\
\text { NISS and LCA } \\
\text { OR (s.e.) }\end{array}$ \\
\hline Base & 743 & 743 & 743 & 743 & 743 \\
\hline ISS & $\begin{array}{c}0.908^{* * *} \\
(0.012)\end{array}$ & & & $\begin{array}{c}0.918^{* * *} \\
(0.010)\end{array}$ & \\
\hline NISS & & $\begin{array}{c}0.940^{* * *} \\
(0.008)\end{array}$ & & & $\begin{array}{c}0.941^{* * *} \\
(0.006)\end{array}$ \\
\hline \multicolumn{6}{|l|}{ LCA Class } \\
\hline Head & & & Reference & Reference & Reference \\
\hline Multi-trauma & & & $\begin{array}{c}1.041 \\
(0.122)\end{array}$ & $\begin{array}{c}1.054 \\
(0.120)\end{array}$ & $\begin{array}{l}0.748^{* *} \\
(0.072)\end{array}$ \\
\hline Abdominal Organ & & & $\begin{array}{l}3.642 * * \\
(1.830)\end{array}$ & $\begin{array}{c}3.206^{* *} \\
(1.533)\end{array}$ & $\begin{array}{l}2.180^{*} \\
(1.007)\end{array}$ \\
\hline Asphyxia & & & $\begin{array}{c}0.179^{* * *} \\
(0.079)\end{array}$ & $\begin{array}{c}0.237^{* *} \\
(0.101)\end{array}$ & $\begin{array}{c}0.121 * * * \\
(0.042)\end{array}$ \\
\hline Burns and other & & & $\begin{array}{c}0.336^{* *} \\
(0.126)\end{array}$ & $\begin{array}{l}0.326^{* *} \\
(0.122)\end{array}$ & $\begin{array}{c}0.183^{* * *} \\
(0.054)\end{array}$ \\
\hline \multicolumn{6}{|l|}{ Fit Statistics } \\
\hline BIC & 847.90 & 846.47 & 858.12 & 792.31 & 809.57 \\
\hline Sensitivity \% & 73.83 & 71.81 & 74.83 & 77.18 & 76.51 \\
\hline Specificity \% & 66.29 & 69.66 & 64.94 & 68.09 & 69.66 \\
\hline Overall \% correctly classified & 69.31 & 70.52 & 68.91 & 71.74 & 72.41 \\
\hline $\begin{array}{l}\text { Hosmer-Lemeshow } \\
\text { goodness-of-fit test }\end{array}$ & 0.358 & 0.931 & 0.768 & 0.369 & 0.653 \\
\hline McFadden $R^{2}$ & 0.186 & 0.187 & 0.176 & 0.220 & 0.224 \\
\hline Adjusted McFadden $R^{2}$ & 0.176 & 0.177 & 0.166 & 0.208 & 0.214 \\
\hline McKelvey and Zavoina $\mathrm{R}^{2}$ & 0.365 & 0.341 & 0.282 & 0.392 & 0.383 \\
\hline Cox Snell $R^{2}$ & 0.221 & 0.223 & 0.211 & 0.257 & 0.261 \\
\hline Nagelkerke $R^{2}$ & 0.299 & 0.301 & 0.285 & 0.347 & 0.352 \\
\hline AUC & 0.777 & 0.782 & 0.775 & 0.803 & 0.806 \\
\hline Specification link test ( $p$-value) & 0.122 & 0.643 & 0.147 & $0.020 * *$ & 0.150 \\
\hline
\end{tabular}

OR $=$ Odds Ratios, s.e. $=$ Standard errors. ${ }^{* * *} p<0.001,{ }^{* *} p<0.05,{ }^{*} p<0.1{ }^{\wedge}$ LCA modified to contain a separate group for Asphyxia injuries. Cut point for sensitivity $\%$, specificity $\%$ and overall $\%$ correctly classified set to proportion good/intact recovery $=0.40$.

\section{Discussion}

Irrespective of country or age, adequately characterising the number and complex pattern of injuries in major trauma patients can be challenging. This study used a novel methodological approach to classify key injury patterns across the whole paediatric major trauma population from Victorian registry data in Australia. For the first time, we are providing a quantified approach to succinctly describe injury patterns to the whole body, rather than relying on descriptions of injuries to individual body regions, and thereby providing data to directly inform injury prevention strategies. The use of exploratory LCA to identify three or four clusters provides an opportunity to target primary injury prevention strategies to prevent these specific injuries, and to focus strategies for optimizing the care of seriously injured paediatric trauma patients.

The identification of key injury patterns into the three main latent injury classes of isolated head injuries, isolated abdominal organ injuries and multi-trauma injuries was found to improve the model fit for both the mortality and 6-month functional outcome models. When considering childhood injury and the paediatric-specific trauma systems developed to prevent and care for such injury, the identification of 'at risk' injury populations, mechanisms and classes is of central importance. However, without accurate risk-adjustment, the design, application and evaluation of injury prevention strategies and trauma care quality improvements may be undermined by misleading epidemiological analyses. Therefore, we have proposed more accurate, paediatric-specific risk-adjustment modelling, to overcome these potential limitations, and so to promote more effective interventions for childhood injury, be that in prevention or trauma care delivery.

The findings highlight the role of isolated head and isolated abdominal injuries as common injury patterns in paediatric major trauma, elevating these for priority in the prevention and management of such injuries in childhood. Traumatic head injuries in children are a leading cause of death and 
a common cause of disability, often occurring in the very young [40]. The abdominal organ latent injury class—predominantly an isolated injury—highlights the importance and relevance of abdominal trauma in childhood injury. Children have relatively larger abdominal solid organs (e.g., spleen, liver and kidneys) compared to adults, which protrude below a more compliant (and so less protective) rib cage. These and other age-specific anatomical differences make children particularly vulnerable to abdominal organ injuries, such as those caused by bicycle handlebars [41].

The complex multi-trauma latent class is another important injury group in children, with approximately one in five patients in our data sustaining more than three injury types. These children exemplify the quality and complexity of injured children, for whom a systematic and paediatric-specific approach to trauma management has been associated with improved delivery and outcomes of care [4]. Not surprisingly, the multi-trauma latent class was significantly associated with higher energy mechanisms of injury including motor vehicle occupants, pedestrian collisions and motorcycle collisions.

Previous studies of paediatric trauma have commonly used composite scores to describe the severity of injuries, e.g., ISS [4,21], while other studies have used the most severe injury [42] or the presence of specific (non-mutually exclusive) injury types [43]. This study identified patterns of injury in paediatric trauma to allow for a more informed and likely impactful modelling of injury in future paediatric trauma research. More parsimonious paediatric trauma statistical modelling was enabled by controlling for either three or four key latent injury classes, rather than each individual injury. The inclusion of injury classes in a model with NISS was superior in terms of all key fit statistics to the other four models. NISS has been shown to outperform the ISS for mortality in more severely injured adults [44], and this study showed that the NISS outperforms the ISS for mortality in more severely injured children.

A strength of this research is the ability of our LCA modelling to contextualise the mortality or functional outcome expectations of an individual injured child in terms of homogenous injury groups. This overcomes an important and recognised limitation of previous injury research, in which the complexity of patterns of injuries sustained has limited inclusion in risk-adjusted statistical models. This research has focussed on the investigation of major trauma injury typologies in children, resulting in the simplification of the complexity of patterns of injuries. The sample size of the cohort used was considerably more than the sample size of 500 as recommended by Finch and Bronk [45] for LCA. a further strength is the improvement in the fit of the statistical models by the adjustment of key injury classes.

A key limitation of this study is its focus on major trauma, given patterns of childhood injury are likely to differ in less-severely injured cohorts. This acknowledged bias notwithstanding, a mature trauma system aiming to reduce death and disability due to injury will similarly focus on patients with major trauma as the cohort of primary concern. Furthermore, the modelling presented in this study may have limited generalizability in non-Australian populations with dissimilar paediatric injury profiles, e.g., far higher rates of firearm trauma in the United States [46] or penetrating injury in the United Kingdom [47]. The initial classification of the sixteen injury groups used in the LCA relied on the broad dichotomous injury groupings denoting the presence or absence of one or more injuries in this cohort. The LCA technique used is an exploratory technique, assuming that latent classes do exist, with the number of classes defined prior to running the analysis. However, this study performed a number of LCA models to test for different number of classes, with and without covariates, using well-established fit statistics and theoretical understanding to decide the final number of classes. Since this is a retrospective study, future research involving a validation cohort from a developed country would be a worthwhile exercise for the evaluation of the performance of the models.

\section{Conclusions}

The key latent injury classes of isolated head, isolated abdominal organ and multi-trauma injuries revealed by this research are important for understanding the patterns of injuries sustained in paediatric 
major trauma, and will inform injury prevention and treatment strategies. It is recommended that researchers consider the inclusion of these injury classes with the NISS to refine future risk-adjusted paediatric injury models when evaluating mortality and functional outcomes.

Author Contributions: J.F.D. contributed to the conception of the study, designed the methodology and conducted the analysis, evaluated all the analyses, and wrote the original draft. B.B. contributed to the conception of the study, evaluated the analysis and provided critical editorial review and editing. W.J.T. contributed to the conception of the study, evaluated the final analysis and provided critical editorial review and editing. B.J.G. contributed to the conception of the study, evaluated the analysis and provided critical editorial review and editing. All authors have read and agreed to the published version of the manuscript.

Funding: The Victorian State Trauma Registry (VSTR) is a Department of Health and Human Services, State Government of Victoria and Transport Accident Commission funded project. This study was supported by a National Health and Medical Research Council (NHMRC) of Australia Project Grant (APP1142325). BB was supported by an Australian Research Council Discovery Early Career Researcher Award Fellowship (DE180100825). WT's role as Director of Trauma Services at The Royal Children's Hospital, Melbourne, is supported by a grant from the Royal Children's Hospital Foundation. BJG was supported by an Australian Research Council Future Fellowship (FT170100048).

Acknowledgments: The Victorian State Trauma Outcome Registry and Monitoring (VSTORM) group is thanked for the provision of VSTR data.

Conflicts of Interest: The authors declare no conflicts of interest.

Research Data Policy: Requests for access to data from the Victorian State Trauma Registry requires relevant ethics approvals and approval from the data custodians, who can be contacted at susan.mclellan@monash.edu or at the following URL: http://www.med.monash.edu.au/epidemiology/traumaepi/traumareg/. Further guidelines for accessing data from the Victorian State Trauma Registry can be found here: http://www.med.monash.edu.au/ assets/docs/sphpm/2016_nov_vstr_data_access_guidelines.pdf.

\section{Appendix A}

Dichotomous injury groupings based on AIS body region and severity

1. Head brain injury (all AIS $3+$ brain injuries)

2. Head skull fracture (all AIS $3+$ skull fractures)

3. Neck injuries (all AIS $3+$ neck injuries)

4. Cervical spine Spinal Cord Injury (SCI) (any AIS 3+ cervical spinal cord injury, including transient neurological signs)

5. Cervical spine non-SCI (any non-SCI AIS 3+ cervical spine injury, including brachial plexus injuries and fractures/dislocations)

6. Thoracolumbar spine SCI (any AIS 3+ thoracic or lumbar spinal cord injury)

7. Thoracolumbar spine non-SCI (any non-SCI AIS 3+ thoracic or lumbar spine injury, including cauda equine and fractures/dislocations)

8. Thoracic organ injury (any AIS $3+$ thoracic organ injury)

9. Skeletal chest injury (any AIS 3+ rib cage or sternum injury)

10. Abdominal organ injury (any AIS $3+$ abdominal organ injury)

11. Pelvis injury (any AIS 3+ pelvis injury)

12. Upper extremity injury (any AIS 2+ injury that includes: amputation, crush injury, clavicle fracture, scapula fracture, humerus fracture and ulna or radius fracture)

13. Lower extremity injury (any AIS 2+ injury that includes: amputation, crush injury, femur fracture, tibia or fibula fracture, hip joint dislocation and knee joint dislocation)

14. Vascular injury (any AIS 3+ vascular injury in any body region)

15. Asphyxia (any AIS 3+ injury related to drowning, asphyxia or suffocation)

16. Burns (any AIS $3+$ burn injury, reflecting a second or third degree burn (partial or full thickness) to $\geq 10 \%$ total body surface area) 


\section{Appendix B}

Table A1. Mortality and 6-month functional outcome logistic regression model confounders.

\begin{tabular}{|c|c|c|c|c|c|}
\hline Mortality & $\begin{array}{l}\text { (1) } \\
\text { ISS }\end{array}$ & $\begin{array}{l}(2) \\
\text { NISS }\end{array}$ & $\begin{array}{c}(3) \\
\mathrm{LCA}^{\wedge}\end{array}$ & $\begin{array}{c}(4) \\
\text { ISS and LCA }\end{array}$ & $\begin{array}{c}(5) \\
\text { NISS and LCA }\end{array}$ \\
\hline Model & $\begin{array}{l}\text { OR } \\
\text { (s.e.) }\end{array}$ & $\begin{array}{c}\text { OR } \\
\text { (s.e.) }\end{array}$ & $\begin{array}{c}\text { OR } \\
\text { (s.e.) }\end{array}$ & $\begin{array}{c}\text { OR } \\
\text { (s.e.) }\end{array}$ & $\begin{array}{c}\text { OR } \\
\text { (s.e.) }\end{array}$ \\
\hline Base & 1259 & 1259 & 1259 & 1259 & 1259 \\
\hline \multicolumn{6}{|l|}{ Age Group } \\
\hline$<1$ year & Reference & Reference & Reference & Reference & Reference \\
\hline $1-5$ years & $\begin{array}{c}1.784 \\
(0.779)\end{array}$ & $\begin{array}{l}2.948^{* *} \\
(1.475)\end{array}$ & $\begin{array}{c}0.910 \\
(0.253)\end{array}$ & $\begin{array}{c}0.766 \\
(0.169)\end{array}$ & $\begin{array}{c}0.880 \\
(0.248)\end{array}$ \\
\hline $6-10$ years & $\begin{array}{c}0.795 \\
(0.205)\end{array}$ & $\begin{array}{l}1.224 \\
(0.404)\end{array}$ & $\begin{array}{l}0.503^{* *} \\
(0.112)\end{array}$ & $\begin{array}{c}0.440 * * * \\
(0.084)\end{array}$ & $\begin{array}{c}0.455^{* * *} \\
(0.135)\end{array}$ \\
\hline $11-15$ years & $\begin{array}{l}0.428^{* * *} \\
(0.071)\end{array}$ & $\begin{array}{c}0.751 \\
(0.201)\end{array}$ & $\begin{array}{c}0.306^{* * *} \\
(0.056)\end{array}$ & $\begin{array}{l}0.259 * * * \\
(0.019)\end{array}$ & $\begin{array}{c}0.275^{* * *} \\
(0.044)\end{array}$ \\
\hline \multicolumn{6}{|l|}{ Sex } \\
\hline Male & Reference & Reference & Reference & Reference & Reference \\
\hline Female & $\begin{array}{c}0.864 \\
(0.090)\end{array}$ & $\begin{array}{l}0.786^{*} \\
(0.097)\end{array}$ & $\begin{array}{c}0.896 \\
(0.087)\end{array}$ & $\begin{array}{c}0.870 \\
(0.083)\end{array}$ & $\begin{array}{l}0.686^{* *} \\
(0.081)\end{array}$ \\
\hline \multicolumn{6}{|l|}{ Major-Trauma Service } \\
\hline No & Reference & Reference & Reference & Reference & Reference \\
\hline Yes & $\begin{array}{c}0.555 \\
(0.426)\end{array}$ & $\begin{array}{c}0.451 \\
(0.373)\end{array}$ & $\begin{array}{c}0.951 \\
(0.765)\end{array}$ & $\begin{array}{c}0.751 \\
(0.664)\end{array}$ & $\begin{array}{c}0.642 \\
(0.578)\end{array}$ \\
\hline \multicolumn{6}{|l|}{ Mechanism } \\
\hline Road Transport Related & Reference & Reference & Reference & Reference & Reference \\
\hline Low/High fall & $\begin{array}{c}0.226^{* * *} \\
(0.078)\end{array}$ & $\begin{array}{c}0.200 * * * \\
(0.068)\end{array}$ & $\begin{array}{c}0.101^{* * *} \\
(0.025)\end{array}$ & $\begin{array}{c}0.218^{* * *} \\
(0.056)\end{array}$ & $\begin{array}{c}0.397^{* * *} \\
(0.090)\end{array}$ \\
\hline \multirow[t]{2}{*}{$\begin{array}{l}\text { Struck or collision with } \\
\text { person/object }\end{array}$} & $2.522 * * *$ & $1.763^{* * *}$ & 1.004 & $2.373^{* * *}$ & $2.529 * * *$ \\
\hline & $(0.402)$ & $(0.377)$ & $(0.088)$ & $(0.243)$ & $(0.452)$ \\
\hline Other & $7.508^{* * *}$ & $12.302^{* * *}$ & $0.646^{* *}$ & 1.160 & $1.896^{* *}$ \\
\hline Year & $\begin{array}{l}(1.269) \\
1.051^{*} \\
(0.029)\end{array}$ & $\begin{array}{l}(2.134) \\
1.044^{* *} \\
(0.023)\end{array}$ & $\begin{array}{c}(0.143) \\
1.050 \\
(0.038)\end{array}$ & $\begin{array}{c}(0.314) \\
1.067 \\
(0.050)\end{array}$ & $\begin{array}{c}(0.596) \\
1.068 \\
(0.050)\end{array}$ \\
\hline IRSAD & $\begin{array}{l}1.055^{* *} \\
(0.024)\end{array}$ & $\begin{array}{l}1.048^{* *} \\
(0.021)\end{array}$ & $\begin{array}{c}0.979 \\
(0.022)\end{array}$ & $\begin{array}{l}1.053^{*} \\
(0.031)\end{array}$ & $\begin{array}{c}1.033 \\
(0.037)\end{array}$ \\
\hline \multicolumn{6}{|l|}{ ARIA } \\
\hline $\begin{array}{l}\text { Inner regional/outer } \\
\text { regional/remote }\end{array}$ & Reference & Reference & Reference & Reference & Reference \\
\hline Major cities & $\begin{array}{l}1.723 * \\
(0.553)\end{array}$ & $\begin{array}{c}1.678 \\
(0.609) \\
\end{array}$ & $\begin{array}{l}1.515^{* *} \\
(0.303)\end{array}$ & $\begin{array}{c}1.306 \\
(0.321) \\
\end{array}$ & $\begin{array}{c}1.317 \\
(0.308) \\
\end{array}$ \\
\hline & (1) & (2) & (3) & (4) & (5) \\
\hline $\begin{array}{l}\text { 6-Month Functional } \\
\text { Outcome Model }\end{array}$ & ISS & NISS & $\mathbf{L C A}^{\wedge}$ & ISS and LCA & NISS and LCA \\
\hline \multicolumn{6}{|l|}{ Age Group } \\
\hline $1-5$ years & $\begin{array}{c}\text { Reference } \\
0.509^{* *} \\
(0.064)\end{array}$ & $\begin{array}{c}\text { Reference } \\
0.432^{* * *} \\
(0.057)\end{array}$ & $\begin{array}{c}\text { Reference } \\
0.655^{* *} \\
(0.094)\end{array}$ & $\begin{array}{c}\text { Reference } \\
0.588^{* *} \\
(0.124)\end{array}$ & $\begin{array}{c}\text { Reference } \\
0.569^{* *} \\
(0.116)\end{array}$ \\
\hline $6-10$ years & $\begin{array}{l}0.373^{* *} \\
(0.154)\end{array}$ & $\begin{array}{l}0.311^{* *} \\
(0.130)\end{array}$ & $\begin{array}{l}0.406^{* *} \\
(0.167)\end{array}$ & $\begin{array}{l}0.333^{* *} \\
(0.173)\end{array}$ & $\begin{array}{l}0.326^{* *} \\
(0.162)\end{array}$ \\
\hline $11-15$ years & $\begin{array}{l}0.275^{* * *} \\
(0.096)\end{array}$ & $\begin{array}{c}0.233^{* * *} \\
(0.085)\end{array}$ & $\begin{array}{l}0.319^{* * *} \\
(0.103)\end{array}$ & $\begin{array}{l}0.255^{* *} \\
(0.108)\end{array}$ & $\begin{array}{l}0.252 * * \\
(0.106)\end{array}$ \\
\hline \multicolumn{6}{|l|}{ Sex } \\
\hline Male & Reference & Reference & Reference & Reference & Reference \\
\hline $\begin{array}{l}\text { Male } \\
\text { Female }\end{array}$ & $\begin{array}{c}0.809^{* * *} \\
(0.049)\end{array}$ & $\begin{array}{c}0.823^{* * *} \\
(0.042)\end{array}$ & $\begin{array}{c}0.851 * * * \\
(0.035)\end{array}$ & $\begin{array}{c}0.816^{* * *} \\
(0.038)\end{array}$ & $\begin{array}{c}0.826^{* * *} \\
(0.034)\end{array}$ \\
\hline \multicolumn{6}{|l|}{ Major-Trauma Service } \\
\hline No & Reference & Reference & Reference & Reference & Reference \\
\hline $\begin{array}{l}\text { No } \\
\text { Yes }\end{array}$ & $\begin{array}{c}0.739 \\
(0.189)\end{array}$ & $\begin{array}{c}0.811 \\
(0.220)\end{array}$ & $\begin{array}{c}0.787 \\
(0.268)\end{array}$ & $\begin{array}{c}0.804 \\
(0.278)\end{array}$ & $\begin{array}{c}0.882 \\
(0.291)\end{array}$ \\
\hline \multicolumn{6}{|l|}{ Mechanism } \\
\hline Road Transport Related & Reference & Reference & Reference & Reference & Reference \\
\hline Low/High fall & $\begin{array}{c}0.786 \\
(0.184)\end{array}$ & $\begin{array}{c}0.876 \\
(0.179)\end{array}$ & $\begin{array}{c}1.004 \\
(0.095)\end{array}$ & $\begin{array}{c}0.991 \\
(0.118)\end{array}$ & $\begin{array}{c}0.978 \\
(0.114)\end{array}$ \\
\hline $\begin{array}{l}\text { Struck or collision with } \\
\text { person/object }\end{array}$ & $0.746^{* * *}$ & 0.886 & $0.779 * *$ & $0.790 * *$ & 0.876 \\
\hline & $(0.048)$ & $(0.080)$ & $(0.056)$ & $(0.062)$ & $(0.085)$ \\
\hline Other & $\begin{array}{c}0.231^{* * *} \\
(0.040)\end{array}$ & $\begin{array}{c}0.205^{* * *} \\
(0.036)\end{array}$ & $\begin{array}{l}0.506^{* *} \\
(0.110)\end{array}$ & $\begin{array}{l}0.489 * * \\
(0.120)\end{array}$ & $\begin{array}{l}0.545^{* *} \\
(0.114)\end{array}$ \\
\hline
\end{tabular}


Table A1. Cont.

\begin{tabular}{|c|c|c|c|c|c|}
\hline Mortality & $\begin{array}{l}\text { (1) } \\
\text { ISS }\end{array}$ & $\begin{array}{l}\text { (2) } \\
\text { NISS }\end{array}$ & $\begin{array}{c}\text { (3) } \\
\text { LCA }\end{array}$ & $\begin{array}{c}\text { (4) } \\
\text { ISS and LCA }\end{array}$ & $\begin{array}{c}\text { (5) } \\
\text { NISS and LCA }\end{array}$ \\
\hline Year & $\begin{array}{l}1.021 \\
(0.013)\end{array}$ & $\begin{array}{l}1.020 \\
(0.017)\end{array}$ & $\begin{array}{c}1.033^{* * *} \\
(0.007)\end{array}$ & $\begin{array}{l}1.020^{* *} \\
(0.007)\end{array}$ & $\begin{array}{l}1.013 * \\
(0.007)\end{array}$ \\
\hline IRSAD & $\begin{array}{l}1.082^{* *} \\
(0.036)\end{array}$ & $\begin{array}{l}1.073 \text { * } \\
(0.043)\end{array}$ & $\begin{array}{l}1.078 \\
(0.049)\end{array}$ & $\begin{array}{l}1.087^{* * *} \\
(0.043)\end{array}$ & $\begin{array}{l}1.078 * \\
(0.044)\end{array}$ \\
\hline $\begin{array}{l}\text { ARIA } \\
\text { Inner regional/outer } \\
\text { regional/remote }\end{array}$ & Reference & Reference & Reference & Reference & Reference \\
\hline Major cities & $\begin{array}{c}1.138 \\
(0.176)\end{array}$ & $\begin{array}{c}1.197 \\
(0.208)\end{array}$ & $\begin{array}{c}1.185 \\
(0.224)\end{array}$ & $\begin{array}{c}1.195 \\
(0.225)\end{array}$ & $\begin{array}{c}1.244 \\
(0.261)\end{array}$ \\
\hline $\begin{array}{c}\text { Fund } \\
\text { Compensable }\end{array}$ & Reference & Reference & Reference & Reference & Reference \\
\hline Non-compensable & $\begin{array}{c}4.754^{* * *} \\
(0.675)\end{array}$ & $\begin{array}{c}4.753 * * * \\
(0.674)\end{array}$ & $\begin{array}{c}5.314^{* * *} \\
(0.576)\end{array}$ & $\begin{array}{c}3.959^{* * *} \\
(0.353)\end{array}$ & $\begin{array}{c}3.998^{* * *} \\
(0.427)\end{array}$ \\
\hline
\end{tabular}

$* * * p<0.001,{ }^{* *} p<0.05, * p<0.1$. Best fit statistics bolded. ^ LCA modified to contain a separate group for Asphyxia injuries. Cut point for sensitivity \%, specificity \% and overall \% correctly classified set to proportion good/intact recovery $=0.40$

\section{References}

1. Kyu, H.H.; Pinho, C.; Wagner, J.A.; Brown, J.C.; Bertozzi-Villa, A.; Charlson, F.J.; Coffeng, L.E.; Dandona, L.; Erskine, H.E.; Ferrari, A.J. Global and national burden of diseases and injuries among children and adolescents between 1990 and 2013: Findings from the global burden of disease 2013 study. JAMA Pediatrics 2016, 170, $267-287$. [PubMed]

2. Mitchell, R.J.; Curtis, K.; Foster, K. a 10-year review of child injury hospitalisations, health outcomes and treatment costs in Australia. Inj. Prev. 2018, 24, 344-350. [CrossRef] [PubMed]

3. Roberts, I.; Hillman, M. Climate change: The implications for policy on injury control and health promotion. Inj. Prev. 2005, 11, 326-329. [CrossRef] [PubMed]

4. Mitchell, R.J.; Curtis, K.; Chong, S.; Holland, A.J.; Soundappan, S.; Wilson, K.L.; Cass, D.T. Comparative analysis of trends in paediatric trauma outcomes in New South Wales, Australia. Injury 2013, 44, 97-103. [CrossRef] [PubMed]

5. Hedström, E.M.; Bergström, U.; Michno, P. Injuries in children and adolescents-Analysis of 41,330 injury related visits to an emergency department in northern Sweden. Injury 2012, 43, 1403-1408. [CrossRef] [PubMed]

6. Mehan, T.J.; Gardner, R.; Smith, G.A.; McKenzie, L.B. Bicycle-related injuries among children and adolescents in the United States. Clin. Pediatr. (Phila) 2009, 48, 166-173. [CrossRef] [PubMed]

7. Vanlaar, W.; McAteer, H.; Brown, S.; Crain, J.; McFaull, S.; Hing, M.M. Injuries related to off-road vehicles in Canada. Accid. Anal. Prev. 2015, 75, 264-271. [CrossRef]

8. Ramakrishnaiah, R.H.; Shah, C.; Parnell-Beasley, D.; Greenberg, B.S. Motorized dirt bike injuries in children. J. Emerg. Med. 2013, 44, 806-810. [CrossRef]

9. Bruns, J.; Hauser, W.A. The epidemiology of traumatic brain injury: a review. Epilepsia 2003, 44, 2-10. [CrossRef]

10. Li, L.; Liu, J. The effect of pediatric traumatic brain injury on behavioral outcomes: a systematic review. Dev. Med. Child Neurol. 2013, 55, 37-45. [CrossRef]

11. Eleraky, M.A.; Theodore, N.; Adams, M.; Rekate, H.L.; Sonntag, V.K. Pediatric cervical spine injuries: Report of 102 cases and review of the literature. J. Neurosurg. Spine 2000, 92, 12-17. [CrossRef] [PubMed]

12. Kemp, A.M.; Dunstan, F.; Harrison, S.; Morris, S.; Mann, M.; Rolfe, K.; Datta, S.; Thomas, D.P.; Sibert, J.R.; Maguire, S. Patterns of skeletal fractures in child abuse: Systematic review. BMJ 2008, 337, a1518. [CrossRef] [PubMed]

13. Peclet, M.H.; Newman, K.D.; Eichelberger, M.R.; Gotschall, C.S.; Garcia, V.F.; Bowman, L.M. Thoracic trauma in children: An indicator of increased mortality. J. Pediatr. Surg. 1990, 25, 961-966. [CrossRef]

14. Baker, S.P.; O'Neill, B.; Haddon, W., Jr.; Long, W.B. The injury severity score: a method for describing patients with multiple injuries and evaluating emergency care. J. Trauma Acute Care Surg. 1974, 14, 187-196. [CrossRef] 
15. Osler, T.; Baker, S.P.; Long, W. a modification of the injury severity score that both improves accuracy and simplifies scoring. J. Trauma Acute Care Surg. 1997, 43, 922-926. [CrossRef]

16. Goodman, L.A. Exploratory latent structure analysis using both identifiable and unidentifiable models. Biometrika 1974, 61, 215-231. [CrossRef]

17. Vermunt, J.K.; Magidson, J. Latent class cluster analysis. Appl. Latent Class Anal. 2002, 11, 89-106.

18. Porcu, M.; Giambona, F. Introduction to latent class analysis with applications. J. Early Adolesc. 2017, 37, 129-158. [CrossRef]

19. Rivara, F.P.; Oldham, K.T. Pediatric trauma care: Defining a research agenda. J. Trauma Acute Care Surg. 2007, 63, S52-S53. [CrossRef]

20. Cameron, P.A.; Finch, C.F.; Gabbe, B.J.; Collins, L.J.; Smith, K.L.; McNeil, J.J. Developing Australia's first statewide trauma registry: What are the lessons? ANZ J. Surg. 2004, 74, 424-428. [CrossRef]

21. Deasy, C.; Gabbe, B.; Palmer, C.; Babl, F.E.; Bevan, C.; Crameri, J.; Butt, W.; Fitzgerald, M.; Judson, R.; Cameron, P. Paediatric and adolescent trauma care within an integrated trauma system. Injury 2012, 43, 2006-2011. [CrossRef] [PubMed]

22. Palmer, C.S.; Gabbe, B.J.; Cameron, P.A. Defining major trauma using the 2008 Abbreviated Injury Scale. Injury 2016, 47, 109-115. [CrossRef] [PubMed]

23. Beck, B.; Teague, W.; Cameron, P.; Gabbe, B.J. Causes and characteristics of injury in paediatric major trauma and trends over time. Arch. Dis. Child. 2019, 104, 256-261. [CrossRef]

24. Gennarelli, T.A.; Wodzin, E. Abbreviated Injury Scale 2005: Update 2008; American Association for Automotive Medicine (AAAM): Des Plaines, IL, USA, 2008.

25. Crouchman, M.; Rossiter, L.; Colaco, T.; Forsyth, R. a practical outcome scale for paediatric head injury. Arch. Dis. Child. 2001, 84, 120-124. [CrossRef] [PubMed]

26. Cameron, A.C.; Miller, D.L. a practitioner's guide to cluster-robust inference. J. Hum. Resour. 2015, 50, 317-372. [CrossRef]

27. Wurpts, I.C.; Geiser, C. Is adding more indicators to a latent class analysis beneficial or detrimental? Results of a Monte-Carlo study. Front. Psychol. 2014, 5, 920. [CrossRef]

28. Vermunt, J.K. Latent class and finite mixture models for multilevel data sets. Stat. Methods Med. Res. 2008, $17,33-51$. [CrossRef]

29. Muthén, B.; Shedden, K. Finite mixture modeling with mixture outcomes using the EM algorithm. Biometrics 1999, 55, 463-469. [CrossRef]

30. Akaike, H. Factor analysis and AIC. In Selected Papers of Hirotugu Akaike; Springer: Cham, Switzerland, 1987; pp. 371-386.

31. Schwarz, G. Estimating the dimension of a model. Ann. Stat. 1978, 6, 461-464. [CrossRef]

32. Lo, Y.; Mendell, N.R.; Rubin, D.B. Testing the number of components in a normal mixture. Biometrika 2001, 88, 767-778. [CrossRef]

33. Celeux, G.; Soromenho, G. An entropy criterion for assessing the number of clusters in a mixture model. J. Classif. 1996, 13, 195-212. [CrossRef]

34. Clark, S.L.; Muthén, B. Relating Latent Class Analysis Results to Variables Not Included in the Analysis. 2009. Available online: https://www.statmodel.com/download/relatinglca.pdf (accessed on 30 January 2020).

35. Agresti, A. An Introduction to Categorical Data Analysis, 2nd ed.; Wiley: New York, NY, USA, 2007.

36. Dinno, A. Nonparametric pairwise multiple comparisons in independent groups using Dunn's test. Stata J. 2015, 15, 292-300. [CrossRef]

37. Sleat, G.K.; Ardolino, A.M.; Willett, K.M. Outcome measures in major trauma care: a review of current international trauma registry practice. Emerg. Med. J. 2011, 28, 1008-1012. [CrossRef] [PubMed]

38. R Core Team. R: a Language and Environment for Statistical Computing. 2018. Available online: https://www.R-project.org/ (accessed on 1 June 2019).

39. Hallquist, M.N.; Wiley, J.F. MplusAutomation: An R Package for Facilitating Large-Scale Latent Variable Analyses in Mplus. Struct. Equ. Modeling 2018, 25, 621-638. [CrossRef]

40. Hyder, A.A.; Wunderlich, C.A.; Puvanachandra, P.; Gururaj, G.; Kobusingye, O.C. The impact of traumatic brain injuries: a global perspective. NeuroRehabilitation 2007, 22, 341-353. [CrossRef] [PubMed]

41. Nataraja, R.; Palmer, C.; Arul, G.; Bevan, C.; Crameri, J. The full spectrum of handlebar injuries in children: a decade of experience. Injury 2014, 45, 684-689. [CrossRef] 
42. Bayreuther, J.; Wagener, S.; Woodford, M.; Edwards, A.; Lecky, F.; Bouamra, O.; Dykes, E. Paediatric trauma: Injury pattern and mortality in the UK. Arch. Dis. Child. Educ. Pract. 2009, 94, 37-41. [CrossRef]

43. Wolyncewicz, G.E.; Palmer, C.S.; Jowett, H.E.; Hutson, J.M.; King, S.K.; Teague, W.J. Horse-related injuries in children-unmounted injuries are more severe: a retrospective review. Injury 2018, 49, 933-938. [CrossRef]

44. Sullivan, T.; Haider, A.; DiRusso, S.M.; Nealon, P.; Shaukat, A.; Slim, M. Prediction of mortality in pediatric trauma patients: New injury severity score outperforms injury severity score in the severely injured. J. Trauma Acute Care Surg. 2003, 55, 1083-1088. [CrossRef]

45. Finch, W.H.; Bronk, K.C. Conducting confirmatory latent class analysis using Mplus. Struct. Equ. Model. 2011, 18, 132-151. [CrossRef]

46. Grinshteyn, E.; Hemenway, D. Violent death rates in the US compared to those of the other high-income countries, 2015. Prev. Med. 2019, 123, 20-26. [CrossRef] [PubMed]

47. Ponsford, R.; Thompson, C.; Paparini, S. We need a renewed focus on primary prevention to tackle youth knife violence. BMJ 2019, 365, 11769. [CrossRef] [PubMed]

(C) 2020 by the authors. Licensee MDPI, Basel, Switzerland. This article is an open access article distributed under the terms and conditions of the Creative Commons Attribution (CC BY) license (http://creativecommons.org/licenses/by/4.0/). 